\title{
Childhood Sexual Abuse: From Conceptualization to Treatment
}

\section{Rachel Lev-Wiesel*}

The Emili Sagol Research Center for Creative Art Therapies, University of Haifa, Israel

\begin{abstract}
Summary: The paper proposes a conceptualization of the experience of fatherdaughter childhood sexual abuse through five traumagenic constructs to further understand the outcomes of it. The uniqueness's of childhood sexual abuse compared to other forms of child abuse, in terms of symptoms and treatment principles, is described.

Findings: The 5-citraumagenic constructs are: Soul's homelessness - the split between the body and mind, captured in time - the present and future as reflections of the past, entrapped in distorted intimacy - lack of authenticity, betrayal entrapment -the all in all betrayal, and re-enactment - the need to relive the experience.
\end{abstract}

Application: Principles required for interventions are drawn according to the traumagenic constructs; intensity, authenticity, and integration between body sensations, feelings, and thoughts.

Keywords: Incest, Theoretical issues; Victim; Clinical issues; Sexual abuse

\section{Introduction}

Childhood sexual abuse (CSA) is defined as a sexual act between an adult or a minor with a child, in which the child is utilized for the sexual satisfaction of the perpetrator [1]. CSA is considered to be a traumatic event since the child is involved in sexual activity that he or she does not fully comprehend, is unable to give informed consent to, or for which the child is not developmentally prepared. As such, these acts violate the laws and/or social taboos of society. There is clear scientific evidence showing that CSA has long term negative psychological effects contingent on variables such as the age of the victim at the onset of the abuse, the severity of violence inflicted upon the victimized child, the extent to which the sexual abuse was performed with "love, care, and tenderness," the duration of the abuse, the identity of the perpetrator, the form of the sexual abuse (exploitation, harassment, exposure to pornography, with or without penetration), the location of the occurrence (home vs. outside the home), and the victim's personal and social resources [2]. Detrimental mental health outcomes that have been consistently associated with CSA include post-traumatic symptoms [3]; depression [4]; substance abuse [5]; helplessness, negative attributions, aggressive behaviors and conduct and eating disorders [6]; and anxiety [7]. More recently, CSA has also been linked to psychotic episodes including schizophrenia and delusional disorder [8] as well as personality disorders [9] and dissociative disorders.

In an attempt to develop a systematic understanding of the outcomes of CSA, Finkelhor and Browne proposed a categorization of the effects of child sexual abuse including four traumagenic dynamics - traumatic sexualization, betrayal, stigmatization, and powerlessness [10]. These dynamics were identified as the core of the psychological injury caused by the abuse, and helped practitioners make assessments of victimized children and anticipate vulnerability factors. However, while some widely accepted treatment protocols and procedures have a solid theoretical basis and considerable anecdotal support for their clinical utility, others have no systematic theoretical foundation and there is little evidence indicating their clinical effectiveness [11].

Based on previous literature showing that CSA varies in both the event contextual characteristics, and the victim's personality and family dynamics, and based on the author's broad research and clinical experience in CSA, the current paper attempts to provide a conceptual model of incest between father and daughter according to five traumagenic constructs: soul's homelessness; captured in time; re-enactment; the betrayal entrapment; and entrapped in a distorted intimacy. These dimensions are suggested to encompass the experience of CSA and useful heuristic devises to conceptualize it. This is based on theory of trauma stating that the brain responds to the traumatic event through various mechanisms such as psychological numbing, shutting down normal emotional responses or activating dissociation: the subject "splits" off part of itself from the experience. I argue that whereas Finkelhor and Brown's model explain some of the uniqueness of child sexual abuse, the constructs of powerlessness and sexualization should be regarded as sub-categories of the constructs suggested in the current paper [10]. The suggested five constructs are the source to the negative short and long term symptoms CSA survivors were found to suffer from (Table 1). The constructs will be described and analyzed next, by using existing evidence from the literature. Implications for practice with children surviving sexual abuse will be suggested.

\section{Soul's Homelessness}

There is a common belief that one's home is one's shelter. It provides safety and predictability, and as such it is experienced as a point of departure and a landing pad. Similarly, one's body is perceived by humans to be their souls' home, and as such the body is attributed the characteristics of a home. The body is the soul's private space. Evidence indicates that people exhibit strong physical and emotional reactions to personal space violations [12] that are produced by the amygdala, particularly if the intimate zone reserved for loved ones, is invaded. People view their personal space serving as buffer vis-à-vis the external world, and it is essential that they experience control and responsibility over it [13]. Sexually penetrating a child's body means breaking into the child's personal space, invading the child's intimate zone. This violation

*Corresponding author: Rachel Lev-Wiesel, The Emili Sagol Research Center for Creative Art Therapies, University of Haifa, Israel, Tel: 972-52-8795849; E-mail: rlev@univ.haifa.ac.il

Received June 05, 2015; Accepted July 09, 2015; Published July 13, 2015

Citation: Lev-Wiesel R (2015) Childhood Sexual Abuse: From Conceptualization to Treatment. J Trauma Treat S4: 016. doi:10.4172/2167-1222.S4-016

Copyright: ( 2015 Lev-Wiesel R. This is an open-access article distributed under the terms of the Creative Commons Attribution License, which permits unrestricted use, distribution, and reproduction in any medium, provided the original author and source are credited. 


\begin{tabular}{|c|c|c|}
\hline Main themes & Categories & Symptoms \\
\hline Soul's homelessness & $\begin{array}{l}\text { - The body no longer serves as a shelter } \\
\text { - The body betrayal- loss of control over the body, loss of safety } \\
\text { - Identification with the perpetrator -turning against oneself, the body } \\
\text { belongs to the perpetrator } \\
\text { - The soul imprisonment within the body } \\
\text { - Split between body and soul- ego fragmentation }\end{array}$ & $\begin{array}{l}\text { - Disgust, noxiousness, hating one's body, distress, anxiety, } \\
\text { depression } \\
\text { - Feelings of not belonging, homelessness } \\
\text { - Self-injurious behaviours } \\
\text { - Eating disorders, neglect of hygiene } \\
\text { - Suicidal thoughts andlor attempts -eliminating the perpetrator within } \\
\text { - Addictions } \\
\text { - Feelings of emptiness, fear to feel } \\
\text { - Self-destructive tendencies } \\
\text { - Dissociation tendencies, high level of persisting dissociation } \\
\text { - Dissociative disorders }\end{array}$ \\
\hline Entrapped in time & $\begin{array}{l}\text { - The present and future are overcome by the past } \\
\text { - Entrapped in the dramatic event - caught within the time cycle } \\
\text { of anticipation, anxiety, sexual victimization, physical relief, and re- } \\
\text { anticipation }\end{array}$ & $\begin{array}{l}\text { - De-realisation } \\
\text { - Depersonalization } \\
\text { - Basic distrust } \\
\text { - Fear and anxiety, heightened paranoid tendencies, fears of intimacy } \\
\text { - Difficulties in sexual relationships } \\
\text { - Distorted sexualisation }\end{array}$ \\
\hline Distorted intimacy & $\begin{array}{l}\text { - Authenticity of the perpetrator-in terms of exposure of unacceptable } \\
\text { sex fantasies and behaviors } \\
\text { - Authenticity of the victim - in terms of intimate exposure of } \\
\text { feelings such as fear, humiliation, and helplessness as well as body } \\
\text { sensations such as sexual arousal } \\
\text { - Beliefs in a painful world } \\
\text { - Symbiosis between perpetrator and victim }\end{array}$ & $\begin{array}{l}\text { - Trusting the perpetrator, distrust of others } \\
\text { - Feelings of terror, anxiety, dissociative episodes, dissociative } \\
\text { disorders } \\
\text { - Feelings of longing to the perpetrator and the intimacy with the } \\
\text { perpetrator in spite of its distortion } \\
\text { - Ambivalent feeling towards the perpetrator } \\
\text { - Self-injurious destructive behaviours, prostitution, seductive } \\
\text { tendency, addiction to sadomasochism sex relations } \\
\text { - Re-enactment as victim or perpetrator role }\end{array}$ \\
\hline Betrayal trauma & $\begin{array}{l}\text { - The perpetrator betrayal } \\
\text { - The family betrayal } \\
\text { - The system betrayal } \\
\text { - The victim betrayal of the family and the perpetrator } \\
\text { - Stockholm syndrome }\end{array}$ & $\begin{array}{l}\text { - Blurred boundaries between victim, perpetrator and other family } \\
\text { members- who am I? who is he? } \\
\text { - Ego fragmentation - use of split, projection, and introjection defence } \\
\text { mechanisms } \\
\text { - dissociative disorders } \\
\text { - basic distrust, feelings of emptiness, loneliness and aloneness } \\
\text { - Survival vs. suicidal attempts } \\
\text { - Insecure or ambivalent attachment pattern } \\
\text { - Narcissism, exploitation tendencies }\end{array}$ \\
\hline - Re-enactment & $\begin{array}{l}\text { - The need to re-enact- to regain control } \\
\text { - A corrective experience } \\
\text { - Addiction to the physical sense of relief at the termination of the } \\
\text { event }\end{array}$ & $\begin{array}{l}\text { - Risk taking } \\
\text { - Self-injurious behaviours } \\
\text { - Feelings of emptiness, need for excitement } \\
\text { - Drug and alcohol addiction } \\
\text { - Ritualism } \\
\text { - Sadomasochism relationships } \\
\text { - Offending others-reversing the roles }\end{array}$ \\
\hline
\end{tabular}

Table 1: Traumagenic constructs, categories and symptomatology.

of the child's body destroys the child's sense of security and trust in the body, and calls into question the body's ability to defend itself and the soul it houses.

When a person's home is broken into by force and the sense of safety is threatened, the resident who experienced this trespass can move to another space, and experience a renewed sense of security. In the case of a violation of a child's private space through bodily penetration, the option of identifying an alternative private and safe space is remote, and the immediate experience is that the body is no longer the metaphoric shelter of the soul but rather transformed into the soul's prison. Plato viewed the relationship between body and soul (soma and psyche) as conflicting and unfortunate. The soul, according to Plato, is a helpless prisoner in the body, compelled to view reality only directly [14]. In contrast, according to Biblical thought, the human body and soul are both sacred, and created by God. They can and must function in harmony to fulfill God's purpose in the world. Emotion, intellect and body are all integral components of a human being, and in that sense there is a need to be integrated [15]. When the soul is imprisoned and abandoned, it has no escape and the damage is commensurate with its importance for existence. Thus, regardless of understandable reasons of why the body surrendered to the perpetrator, including being overwhelmed by anxiety (loss control over the sphincters), physical inferiority, or being in a state of frightened immobility, once it failed to defend the soul some devastating consequences can be expected in the survivor's existential experience as a whole. This failure to ward off the perpetrator is experienced as the body's betrayal of the soul - defined as a form of deception or dismissal of prior life assumptions, a breaking or violation of a presumptive psychological and social contract (trust, or confidence). This is likely to result in a conflict which produces a split between the soul and body. The repulsive, uncontrolled, contaminated traitor body deserves to be punished. However, being imprisoned within the body and forced to continue relying on it for mere survival, the soul can choose between three options: identify with the aggressor by taking onto itself the perpetrator role (often long time after the abuse had ceased), splits itself away from the body through employment of dissociation and ignoring the bodily needs, or, retaliate by punishing the body for its betrayal. Each option can be manifested in a variety of symptoms on a continuum of severity from suicidal attempts, selfinjurious behaviors, substance abuse, eating disorders, promiscuity, addiction to sadomasochistic sexual activities, to neglect of hygiene, depression, feelings of emptiness, etc. (Table 1).

\section{Captured in Time}

People can be described as time travelers: they draw on past memories, experience the present and look forward to the future [16]. The way these journeys in time are integrated in experience makes 
a crucial difference to how well they do in life and how content and satisfied they are [17]. In that respect, time perspective - whether the person tends to get stuck in the past, live only for the moment, or is enslaved by ambitions concerning the future - are good predictors of educational and career success, general health, and happiness [18]. CSA Survivors often re-experience the trauma mentally and physically when they experience cues or triggers associated with the previous traumatic events, at times these occurrences cause re-traumatization [19]. When re-experiencing the trauma happens occasionally, survivors feel they will not be able to be released from their past. As a result, feelings of despair, loss of self-esteem, and depression are heightened. In that sense, the survivors' present and future become reflections of the past. It is not surprising, therefore, that survivors tend to view life situations and relationships through the prism of the abuse and their previous relationship with the abuser (trust, danger, etc.).

The life of the victimized child revolves around the abuse, waiting before it occurs, during, and waiting for the next abusive event after it happens. In this respect, the abuse and life become one; the abuse is the only real certainty to come. The figure/ground phenomenon alters their perception in a manner that, whereas the reality outside the abusive experience (school, friends, etc.) fade into the background becomes defocused and unreal; the ever domineering background is the abuse; symptom of de-realization and time loss, develop. Data indicate that the sense of time as duration (time as it is felt) develops by early infancy, while time as perspective (time as a concept) develops by late infancy or early toddlerhood [20]. Investigators [21] propose that the sense of time develops out of perception of bodily function and is intimately related to the development of the sense of self. The sense of time further evolves as a function of psychosexual and other developmental stages. Not surprisingly, therefore, that the younger the victim of sexual abuse is, the more severe the time dependent outcomes in terms of psychosocial symptomatology and health [22].

\section{Time cycling}

CSA event is an intense and extremely stressful situation in which the time is likely to be experienced by the victim as infinite. When this event becomes continual, the child learns to identify the signs of the impending occurrence, to recognize the highest hit point in the momentary immediate event, and the signals indicating that the specific traumatic occurrence came to an end. When the perpetrator leaves, whether or not the child is physically injured, physical relief emerges - a sensation of natural relaxation (the body releases chemicals, muscles relax, the heart rate slows down, and blood flow to the brain increases) due to an experiential distancing from the source of stress (the perpetrator). However, this relaxation does not last long. Anxiety and fear gradually increase due to decrease of the dissociation mechanisms employed during the event itself, and dreading the next inevitable frightening encounter with the abuser. Thus, the child is circling from dreading the inevitable encounter with the abuser, experiencing the abuse, relief when it temporally ends, to re-dreading the next abusive event. This creates a psychological construct of being entrapped in time, and exhibited in disorientation in time, trance, persistent dissociation, and loss of time [23] (Table 1).

\section{Entrapped in Distorted Intimacy}

Some of the repercussions of incestuous relationship, specifically father-daughter incest include a marked sense of isolation from the family, difficulty to control anger, problems in forming and maintaining a trusting relationships, and inability to establish intimate relationships with people other than the perpetrator [24]. Courtois suggested that the impact of incest is highly subjective and, thus, not easily predicted from mere knowledge of the circumstances [25]. In a meta-analysis of studies focusing on incest, Rind and Tromovitch generated controversy by suggesting that CSA does not always cause pervasive harm, especially when the child described the encounter as consensual, and when the incestuous daughter is eager to assume adult role and is gratified by her fathers' attention [26]. Evidence indicated that the father-daughter distorted intimacy is often encouraged, tolerated or denied by other members of the family including the mothers [24].

Whereas normative intimacy involves self-disclosure, positive affection, closeness, and interdependence between the involved partners [27], an incestuous relationship involves self-disclosure and self-revealing of unacceptable fantasies, behaviors, sexual arousal, feelings of fear, shame and horror, negative closeness and interdependence between the parties involved. The victimized child naturally internalizes a distorted model of intimacy which harms his or her future abilities to establish fulfilling intimacy and leads to loneliness, depression, lower self-esteem, anxiety, and less relational satisfaction [28]. Since intimacy is a vital human need for mental health and psychosocial adjustment [29], and close intimate relationships are the most important source for individual well-being and a sense of meaning in life [28], the survivor is likely to either yearn to reestablish the past distorted intimate relationships, reenact the distorted intimacy with others, or avoid any close relationships for fear of intimacy [30]. Based on clinical observations, it can be assumed that the greater the emotional ambivalence towards the perpetrator, the greater the entrapment in the distorted intimacy is likely to be, as well as greater severity of symptoms such as addiction to pornography or involvement in sadomasochistic sexual activities.

From psychodynamic perspective, having been involved in such a distorted intimacy, being played as a puppet by the perpetrator, having the perpetrator as the key significant other from an early age, is bound to severely affect the victim's self- identity which will later affect the ability to develop a healthy intimacy with another. When the abuse is prolonged and repeated, separation-individuation cannot be accomplished. The ability for authenticity as a result, is tumbledown. The victimized child is caught in a world of pseudo appreciation, visibility and acknowledgement by the perpetrator who has become the main pillar of a distorted world. Hirsch claimed that psychological coping with severe traumatic aggression in the family can be handled by identification acceptance of, and submission to, the overwhelming power [31].

The victim interjects the terror, identifies himself or herself with it and so remains a victim throughout his or her life by repetition compulsion. Anna Freud has used the term 'identification with the aggressor' - defined as an unconscious process in which a person adopts the perspective or behavior patterns of a captor or abuser. Along the same lines, abused children tend to show more ego-strength and the ability to defend themselves aggressively; they have attacked their fear by identifying with it. According to Freud, this is a defense mechanism used to "protect the self from hurt and disorganization." The child learns to reduce his or her anxiety by changing from the passive to the active role [32]. This is one possible explanation of why abused children become abusive adults or develop complex PTSD [33]. The need to adapt and function in contrasting realities (the secret abusive world vs. the external world), in addition to being subjected to a prolonged repetitive trauma, was found to often result in developing dissociative disorders which further damage the ability of the survivor to establish healthy intimate relationships [34] (Table 1). 


\section{The Betrayal Entrapment}

CSA is a betrayal in the basic belief that the world is a place where children are protected from evil, whether or not the perpetrator is an acquaintance or a stranger, a peer or a family member, if it was expected or not. Adults are naturally perceived by children as their protectors and home as a safe shelter. When the perpetrator is a family member and other family members ignore or encourage the abuse, the child loses trust and confidence in the significant others as well as in the belief that the world is a safe place. However, not only the direct perpetrators are perceived to betray the child's trust in case of CSA- the external systems, such as teachers and friends, are often perceived as traitors as well [33]. Even if the child does not disclose to them, his/her natural expectation is that adults in general and those who care in particular will see and understand the situation.

Freyd was the first to use the term "betrayal trauma" to explain why victims might repress the memories of harmful experiences inflicted upon them by a person on whom they rely [35]. Substantially similar to the theory of dissociative amnesia, the theory of betrayal trauma DePrince, et al., suggests that social utility might cause an individual to undergo traumatic amnesia in favor of maintenance of a relationship perceived as needed for survival [36]. Hensley defines betrayal trauma as biopsychosocial harm caused by an actual or perceived violation of a psychological contract by a person (or people) upon which the victim relies for some aspect of his or her wellbeing. Hensley argues that betrayal trauma is far more injurious than physical and other traumas in that it destabilizes the mental model, schemas, and psychological contracts the victim has established to see, understand, and respond to through life events and, thus, extreme biopsychosocial distress is the likely result [37]. It violates the victim's understanding of rules, roles, relationships, respect, morals, ethics, and values, which are the core tenets of the psychological contract. A return to equilibrium requires the individual to redefine one or more of these tenets.

However, the abused child might also perceive himself/herself as a betrayer. In cases in which the perpetrator is a close family member, as time passes from the onset of abuse and nothing is reported, the victim's feelings of guilt concerning the abuse increase. The mere participation in the sexual interaction becomes more difficult when the victim has feelings of love toward the perpetrator, or the victim feels unique and chosen by receiving the perpetrator's affections [33]. These situations increase the child's feelings of guilt on one hand and the feelings of being special on the other. Furthermore, the mere need or will to reveal the secret is experienced as a betrayal. The betrayal deserves punishment; the betrayer deserves to be punished, if not by others, by oneself. As already mentioned in the Soul's homelessness section, an additional aspect to the betrayal entrapment stems from the victim's body of the soul particularly if the body responded with sexual arousal during the sexually abusive event, resulting in symptoms such as eating disorders, addictions, neglect of hygiene, self-injurious behavior, and suicidal acts.

A major consequence of the overall betrayal is the loss of the ability to be authentic across situations. The child learns to survive in a world filled with double messages: Do not lie, but do not tell the truth. Sex is forbidden, but hidden sex is allowed. Love is painful. Parents are an unsafe shelter. Life dimensions are disconnected from one another, and energy is invested in protecting information traveling from one dimension to the other. Different personas appear or disappear according to the life situation. Like an actor on a stage who plays all the roles, so does the victimized child, especially in a family where incest occurs. In these situations, the child does not have the opportunity to be himself. In each dimension, he must become someone else as required by others. In childhood, the personality is still developing, but these situations cause the victim to constantly perform different roles and reduce the ability to authentically experiment with roles, a requirement for healthy development. The ability of the victimized child to be him/ herself is denied as the boundaries between who he/she is and who he/she needs to be are penetrated. In addition, the child performs in context of a larger than life number of "provinces of meaning" (a term used by Alfred Shutz in Hindess [38]. As in the theater, the curtain is up and a whole other world appears. He/she enters, than the curtain goes down and he/she is expected to go back to the real world. But is there a real world? Such changes are the source of much instability and insecurity that along with loss of authenticity lead to severe identity liability.

Authenticity is the basis for intimacy, its lack further prevents the victim from building an intimate relationship that is not distorted with another person. Thus, betrayal at any stage of the socio-developmental cycle results in extreme biopsychosocial distress; destabilizes the psychological contracts by which one trusts, and negates important aspects of viable strategies by which the person copes with life events [37] (Table 1).

\section{Re-enactment}

Chu posited that reenacting a past trauma is a way an individual attempts to master it, yet lifelong reenactments and re-exposure to trauma rarely result in resolution and mastery [39]. Van der Kolk and Greenberg claimed that CSA can lead to ego deficits that render an individual susceptible to both reenactments and re-victimization as a result of their addiction to trauma [40,41]. Reenactments caused by rigidified defenses, lead to reenactments of the problems that the original defenses sought to avoid. The effort to master the trauma is a maladaptive mechanism and the strategy results in continued distress and difficulties for the individual. Reenactments following CSA are presented in the forms of self-harming behaviors, actively reenacting a past trauma [42], or abuse of others [43]. Self-harming behaviors in adult survivors as active reenactments of childhood sexual trauma can be more reflective of a maladaptive defensive posture than an adaptive process [44]. Van der Kolk and van der Hart posited that survivors of CSA are addicted to the trauma and, therefore, may try to recreate it due to overstimulation of sexualization [45]. Such individuals have reported feeling bored, apprehensive, and anxious when not experiencing some form of activity reminiscent of their trauma. For children who experience trauma, these experiences became synonymous with relationships, and the child is often in a constant state of arousal due to fear, rage, hyper alertness, or anxiety. This constant arousal impacts the child's biochemistry and inhibits a return to a baseline. Thus, as an adult, the individual may be addicted to an excitement which is painful, but at the same time he/she finds this excitement pleasurable and comfortable. Further, van der Kolk and van der Hart reported that high levels of stress such as hyper arousal that is created by a trauma, activate the physiological opioid systems, may create a cycle of dependence and withdrawal [45].

An additional aspect for reenactment could stem from the desire to re-experience the momentarily relief experienced when the abuser releases the victim and leaves the scene. During the time of the trauma, endorphin levels remain elevated and help numb the emotional and physical pain of the trauma. However, after the trauma is over, endorphin levels gradually decrease and this may lead to a period of endorphin withdrawal that can last from hours to days. This period of endorphin withdrawal may initially be felt as a relief, but gradually 
produce emotional distress and contribute to other symptoms of posttraumatic stress disorder [46]. Thus, the brief sensation of physical and emotional relief may act as a reward to the traumatic event and become an addictive factor to reenactment (Table 1).

\section{From Conceptualization to Practice}

Understanding and treating survivors of childhood sexual abuse is a complex process. Unlike adults, children who are sexually abused are traumatized during the most critical period of their lives: when assumptions about self, others and the world are being formed; when their relations to their own internal states are being established; and when coping and relationship skills are first acquired. In light of its critical importance, intervention should evaluate the following issues: the intensity and the severity of the abuse, the meaning attributed to the symptoms by the child, the form and level of severity of the dissociation, the variance of feelings towards the perpetrator and other significant figures, the tendency to reenact and its purpose, and the survivor's time perception and sense of time. In addition, the therapist is required to be able to contain the victim's pornographic story, the suffering, and the contrasting feelings towards the perpetrator while being attuned to nuances in order to avoid possible projective identification processes. Note that the intervention techniques implemented should be victim's age-related as well as victim's dynamic familial specific situation.

Healing unresolved traumas from early life requires accessing the events that produced the trauma, re-experiencing them cathartically in the original ego state, and reframing the meaning of the experience through corrective emotional experiences [47]. Corrective experience is defined as a process by which a patient gives up old behavior patterns and learns or relearns new patterns by re-experiencing early unresolved feelings and needs through re-exposure under favorable circumstances to an emotional situation with which one could not cope in the past. Hartman and Zimberhoff suggested three categories for corrective experience: (1) building ego strength through release of shame and reclaiming worthiness; (2) building agency through release of helplessness and reclaiming personal power; and (3) building authenticity through release of dissociation and identification and reclaiming self-reflective identity [48].

In order for the therapeutic process to become a corrective experience, the elements of the sexual abuse should be used yet lead towards growth rather than towards re-captivity. The following are the characteristics of the past traumatic experience that should be addressed within the therapy: intensity, authenticity, and body sensations, emotions and thought involvement.

\section{Intensity}

The sexual abuse event is an intensive experience in terms of the time (length of each abusive event and duration of the overall abuse) and the dynamic cycle of each event (before the hit point, the hit point, the aftermath, and relief). In contrast to the extreme intensity that is characteristic of CSA (particularly in cases of incest), the usual therapy process is less intense, consisting of a series of one-hour sessions, once a week for a duration that is decided by both parties involved. The previous procedure is based on the clinicians' recognition that sexual abuse of a child is a gross violation of boundaries, therefore, many therapists put close attention to maintaining therapeutic boundaries when treating survivors of CSA. However, the time breaks between the sessions, are likely to heighten dissociative mechanisms employed in order to lower overwhelming by feelings of anxiety, rage, or agony which might cause clients to regress to the starting point. In the next session, the victimized client may arrive in a different state that will not allow the emotional continuity from the point that was reached during the previous session. Returning to the starting point, again and again, even if the relationship with the therapist is perceived as a safe place might unintentionally strengthen the uncontrollable activation of dissociative mechanisms. Thus, it will keep the victim in a state of survival and resilience, yet prevent PTG. Since the time framework and intensity of therapy of sexual abuse survivors has a psychodynamic meaning, it seems worthwhile to allow a continuous communication between the therapist and client which can be achieved presently by technology (emails, phone calls) and other means such as journal writings.

\section{Authenticity}

Authenticity is essentially an encounter attitude. Being authentic is a precondition to enter dialogue in which each partner acknowledges the other, is being open and revealing himself or herself. Authenticity involves sensory and emotional qualities rather than purely cognitive or verbal qualities.

As a result of the overall betrayal, survivors of incest tend to mistrust others and close relationships in general. Paradoxically, the one person they had learned to trust due to his/her persistent and authentic though distorted conduct is the perpetrator. During the sexual abuse event, the perpetrator's unacceptable, distorted, twisted desires are revealed, whether intentionally or unintentionally. The child also is exposed to the perpetrator in terms of his/her inferiorities, helplessness, and weaknesses. Due to CSA survivors' high sensitivity to unauthenticated behavior on one hand and basically expecting it on the other hand, therapists who treat survivors of incest should be aware of their own responses and behaviors and be as authentic as they can from the perspective of the matching of their inner thoughts, beliefs, and feelings with their outer presentation and behaviors [49].

\section{Integration between Body Sensations, Feelings and Thoughts}

Life experiences, particularly traumatic events, are stored not only in thoughts and emotions but deeply in the body at a cellular level. CSA injures the body and harms the psyche. In order to survive this abuse, the child needs to employ dissociation which separates information from one dimension (body sensation, feelings, and thoughts) and does not let it reach the other dimension. The victimized child who is accustomed to dealing with sex has learned the rules of dissociation, thus she detached herself from her body, an act which enabled her to be "as if" comfortable with the sexual interaction. Sometimes, the survivor equates sex with love.

It is necessary to address all three dimensions, the body, feelings and thoughts, within the therapy, in order to reintegrate the mind and body, strengthen consciousness and awareness of the present moment, and thereby enable one's future perception to be released of the past. Through physical, emotional and cognitive integrating processes, the need to use dissociation decreases with time.

\section{Conclusion}

In order for the therapeutic process to become a corrective experience, the elements of the sexual abuse should be used yet lead towards growth rather than towards re-captivity. Corrective experience in terms of cradling the victimized child without the time and intensity dimensions that symbolically parallel the abusive experience might unintentionally entrap both the therapist and the client. The client's 
need for warmth and containment from the therapist and his/her fear of abandonment might cause him/her to preserve his/her role as helpless and needy which might in turn strengthen the therapist's savior fantasy. Both the therapist and the client therefore will then preserve the entrapment state, only in reversed covert roles, the victimized client as the captor and the warm therapist as the prisoner, maintaining positive feelings towards the therapeutic process itself and towards each other in a long-term therapeutic relationship with parental expressions of love and protection.

It is imperative that therapists of sexual abuse survivors will ask themselves during each phase of the therapeutic process the following questions: Is the sexual abuse the client's dominant problem? Is the sexual abuse traumatic? What was the cause of the trauma during the experience? What is the meaning of the sexual abuse for the victim? What is the meaning of the perpetrator for the victim? What are the symptoms? What is the main symptom? What does it represent? What is the secret the client hides from himself? Who are the internal voices and what do they say? Who are the significant figures and what are their main messages to the client? What is the weight of each message? What personal and social resources does the client have? What does the therapist represent to the client? What type of transference occurs between both the client and the therapist? What does the therapist feel toward the client? What is the therapist reluctant to hear? What are the therapist's body sensations, feelings, and thoughts that are aroused in the presence of the client? What does the client dare not say to the therapist and why? In addition to continuous supervision, answering these questions might help to detect projective identification processes and pathological patterns, such as recreating the entrapment. Since this paper focused on father daughter incest relationship it seems that further research is needed to broaden the understanding and difference of father-son as well as mother-son incest relationship.

\section{References}

1. Briere J (1992) Child Abuse Trauma: Theory and Treatment of the Lasting Effects. Sage Publications, London, UK.

2. Laaksonen $T$, Sariola $H$, Johansson A, Jern $P$, Varjonen $M$, et al. (2011) Changes in the prevalence of child sexual abuse, its risk factors, and their associations as a function of age cohort in a Finnish population sample. Child Abuse Negl 35: 480-490.

3. Cantón-Cortés D, Cantón J (2010) Coping with child sexual abuse among college students and post-traumatic stress disorder: the role of continuity of abuse and relationship with the perpetrator. Child Abuse Negl 34: 496-506.

4. Ferguson CJ, Rueda S, Cruz A, Ferguson D, Fritz S, et al. (2008) Violent video games and aggression: Causal relationship or byproduct of family violence and intrinsic violence motivation? Criminal Justice and Behavior 35: 311-332

5. O'Leary P, Gould N (2009) Men who were sexually abused in childhood and subsequent suicidal ideation: Community comparison explanations and practice implications. British Journal of Social Work 39: 950-968.

6. Jonas S, Bebbington P, McManus S, Meltzer H, Jenkins R, et al. (2011) Sexual abuse and psychiatric disorder in England: results from the 2007 Adult Psychiatric Morbidity Survey Psychological Medicine. Psychol Med 41: 709-719.

7. Banyard VL, Williams LM, Siegel JA (2001) Understanding links among childhood trauma, dissociation, and women's mental health. Am J Orthopsychiatry $71:$ 311-321.

8. Bendall S, Jackson HJ, Hulbert CA, McGorry PD (2011) Childhood trauma and psychosis: An overview of the evidence and directions for clinical interventions. Informit 89.

9. Cutajar MC, Mullen PE, Ogloff JR, Thomas SD, Wells DL, et al. (2010) Psychopathology in a large cohort of sexually abused children followed up to 43 years. Child Abuse Negl 34: 813-822.

10. Finkelhor D, Browne A (1985) The traumatic impact of child sexual abuse: a conceptualization. Am J Orthopsychiatry 55: 530-541.
11. Lev-Wiesel $R$ (2008) Child sexual abuse: a critical review of intervention and treatment modalities. Children and Youth Services Review 30: 665-673.

12. Kennedy DP, Gläscher J, Tyszka JM, Adolphs R (2009) Personal space regulation by the human amygdala. Nat Neurosci 12: 1226-1227.

13. Hall ET (1966) The Hidden Dimension. Anchor Books, New York, NY, USA.

14. Ogden CK (1928) Plato theory of ethics. Routledge \& Kegan Paul Ltd., London, UK.

15. Urbach G (1979) The flavor of milk fat. In Proceedings of Milk Fat Symposium held at dairy research laboratory, Division of Food Research, CSIRO, Australian Society of Dairy Technology, Melbourne, Australia, 18-27.

16. Zimbardo PG, Boyd JN (1999) Putting time in perspective: A valid, reliable individual-differences metric. Journal of Personality and Social Psychology 77 : 1277-1288.

17. Carstensen LL (2006) The influence of a sense of time on human development. Science 312: 1913-1915

18. Kauffman D, Husman J (2004) Effects of time perspective on student motivation: Introduction to a special issue. Educational Psychology Review 16: 1-7.

19. Carlson EB, Ruzek J (2005) Effects of traumatic experiences: A national center for PTSD fact sheet. National Center for Post-Traumatic Stress Disorder.

20. Droit-Volet S, Meck WH (2007) How emotions colour our perception of time. Trends Cogn Sci 11: 504-513

21. Butler WM (1999) Psychoanalytic time: A developmental perspective. Canadian Journal of Psychoanalysis 7: 303-319.

22. Briere J, Elliott DM (1997) Psychological assessment of interpersonal victimization effects in adults and children. Psychotherapy: Theory Research \& Practice 34: 353-364

23. Drake L, Duncan E, Sutherland F, Abernethy C, Henry C (2008) Time perspective and correlates of well-being. Time \& Society 17: 47-61.

24. Seidman BT, Marshall WL, Hudson SM, Robertson PJ (1994) An examination of intimacy and loneliness in sex offenders. Journal of Interpersonal Violence 9: 518-534.

25. Courtois CA (1999) Recollections of sexual abuse: Treatment principles and guidelines. W. W. Norton \& Co., New York, NY, USA.

26. Rind B, Tromovitch $P$ (1997) A meta-analytic review of findings from national samples on psychological correlates of child sexual abuse. Journal of Sex Research 34: 237.

27. Downey L (2001) Intimacy and the relational self. The Australian and New Zealand Journal of Family Therapy 22: 129-136.

28. Pielage BS, Luteijn F, Arrindell AW (2005) Adult attachment, intimacy and psychological distress in a clinical and community sample. Clinical Psychology and Psychotherapy 12: 455-464.

29. Descutner CJ, Thelen MH (1991) Development and validation of a fear-ofintimacy scale. Journal of Consulting and Clinical Psychology 3: 218-225.

30. Firestone RW, Catlett J (1999) Fear of intimacy. American Psychological Association, New York, NY, USA.

31. Hirsch M (1996) [2 forms of identification with the aggressor--according to Ferenczi and Anna Freud]. Prax Kinderpsychol Kinderpsychiatr 45: 198-205.

32. Freud A (1936) The ego and the mechanisms of defense. Hogarth Press, London, UK.

33. D'Andrea W, Ford J, Stolbach B, Spinazzola J, van der Kolk BA (2012) Understanding interpersonal trauma in children: why we need a developmentally appropriate trauma diagnosis. Am J Orthopsychiatry 82: 187-200.

34. Schalinski I, Elbert T, Schauer M (2011) Female dissociative responding to extreme sexual violence in a chronic crisis setting: the case of Eastern Congo. J Trauma Stress 24: 235-238.

35. Freyd JJ (1994) Betrayal-trauma: Traumatic amnesia as an adaptive response to childhood abuse. Ethics \& Behavior 4: 307-329.

36. DePrince AP, Brown LS, Cheit RE, Freyd JJ, Gold SN, et al. (2012) Motivated forgetting and misremembering: perspectives from betrayal trauma theory Nebr Symp Motiv 58: 193-242.

37. Hensley AL (2009) Betrayal trauma: Insidious purveyor of PTSD. In: Dougherty $\mathrm{G}$ (ed.) Return to equilibrium: Proceedings of the 7th Rocky Mountain Region 
Citation: Lev-Wiesel R (2015) Childhood Sexual Abuse: From Conceptualization to Treatment. J Trauma Treat S4: 016. doi:10.4172/2167-1222. S4-016

Disaster Mental Health Conference, Ann Arbor, Ml: Loving Healing Press 105-148.

38. Hindess B (1972) The phenomenological sociology of Alfred Schutz. Economy \& Society 1: 1-27.

39. Chu JR (1998) Rebuilding shuttered lives: The responsible treatment of complex posttraumatic and dissociative disorders. John Wiley \& Sons, New York, NY, USA

40. van der Kolk BA, Greenberg MS (1987) The psychobiology of the trauma response: Hyperarousal, constriction, and addiction to traumatic re-exposure. In: van der Kolk BA (ed.), Psychological trauma American Psychiatric Press, Washington, DC, 63-87.

41. Russell DEH (1986) The secret trauma: Incest in the lives of girls and women. Basic Books, New York, NY, USA.

42. Salter D, McMillan D, Richards M, Talbot T, Hodges J, et al. (2003) Development of sexually abusive behaviour in sexually victimised males: a longitudinal study. Lancet 361: 471-476.

43. Lalor K, McElvaney R (2010) Child sexual abuse, links to later sexual exploitation/high-risk sexual behavior, and prevention/treatment programs. Trauma Violence Abuse 11: 159-77.

44. Kaufman J, Zigler E (1989) The intergenerational transmission of child abuse In: Cicchetti D, Carlson V (eds.) Child maltreatment: Theory and research on the causes and consequences of child abuse and neglect. Cambridge University Press, Cambridge, UK, 129-150.

45. van der Kolk BA, van der Hart O (1989) Pierre Janet and the breakdown of adaptation in psychological trauma. Am J Psychiatry 146: 1530-1540.

46. Volpicelli J, Balaraman G, Hahn J, Wallace H, Bux D (1999) The role of uncontrollable trauma in the development of PTSD and alcohol addiction. Alcohol Res Health 23: 256-262.

47. Bridges MR (2006) Activating the corrective emotional experience. J Clin Psychol 62: 551-568.

48. Hartman D, Zimberoff D (2004) Corrective emotional experience in the therapeutic process. Journal of Heart-Centered Therapies 7: 3-84.

49. Burks DJ, Robbins R (2012) Psychologists' authenticity: implications for work in professional and therapeutic settings. Journal of Humanistic Psychology 52: 75-104.
This article was originally published in a special issue, Post Traumatic Stress Disorders handled by Editor(s). Dr. Allison N. Sinanan, Stockton University, NJ, USA 